Research Article

\title{
Differences between the Anthropometric Measurements of Serbian and Libyan Male Passenger Car Drivers
}

\author{
Zorica Veljkovićc ${ }^{1},{ }^{1}$ Aleksandar Brkić, ${ }^{2}$ Vesna Spasojevic Brkić ${ }^{(D)},{ }^{1}$ Milivoj Klarin, ${ }^{3}$ \\ Ahmed Essdai, ${ }^{4}$ and Sanja Stanisavljev ${ }^{3}$ \\ ${ }^{1}$ University of Belgrade, Faculty of Mechanical Engineering, Belgrade 11000, Serbia \\ ${ }^{2}$ Faculty of Mechanical Engineering, Innovation Center, Belgrade 11000, Serbia \\ ${ }^{3}$ Technical Faculty "Mihajlo Pupin", University of Novi Sad, Zrenjanin 23000, Serbia \\ ${ }^{4}$ Faculty of Engineering, Misurata University, Misurata, Libya \\ Correspondence should be addressed to Zorica Veljković; zveljkovic@mas.bg.ac.rs
}

Received 17 March 2020; Revised 11 July 2020; Accepted 15 July 2020; Published 17 August 2020

Academic Editor: Alessandro Gasparetto

Copyright (c) 2020 Zorica Veljković et al. This is an open access article distributed under the Creative Commons Attribution License, which permits unrestricted use, distribution, and reproduction in any medium, provided the original work is properly cited.

\begin{abstract}
The collection and analysis of anthropometric characteristics for various passenger car user populations is a very important predecessor of the design process. The first aim of this survey is to collect up-to-date anthropometric data for male passenger car drivers in Serbia and to collect those data for the first time in Libya. The second aim of this survey is to compare the collected data and enable further modeling using both univariate and multivariate operators' models from both samples. Anthropometric measurements on standing height, sitting height, lower leg length, upper leg length, shoulder width, hip breadth, arm length, and foot length were collected for 921 Serbian and 300 Libyan male drivers. Results show that, for Serbian male drivers, a correlation between variables exists in $67.85 \%$ cases, while for Libyan male drivers, a correlation between variables exists in $39.28 \%$ cases. The comparison of mean values between variables for Serbian and Libyan male drivers showed that, beside shoulder width, all others have significantly higher values for Serbians than for Libyikans. Consequently, there are different interior space dimensions of the vehicle obtained: for Serbian drivers, interior space dimensions amounted to $1500 \times 561 \times 1230 \mathrm{~mm}$ and for Libyan drivers amounted to $1400 \times 591 \times 1155 \mathrm{~mm}$ which are useful to passenger car designers in eliminating existing anthropometric inconsistencies.
\end{abstract}

\section{Introduction}

Passenger cars today are designed to fit user needs, but there are still many physical, cognitive, and sensory issues that have not been solved to fit user needs. The reason for that lies in the fact that designing a passenger car involves the integration of inputs from many disciplines, including ergonomics. It is very important that the people inside, especially the driver, feel comfortable and do not experience any awkward postures or a high level of physical efforts, such as excessive bending, turning, twisting, stretching, leaning, and the hitting of parts of the body against vehicle components [1].

Driving a car is a very complex and dynamic task [2]. Viviani et al. [3] determine the criteria that define a successful outcome to the passenger car design process in terms of comfort, performance, and health and safety. These factors together benefit the production companies' productivity and efficiency [4]. The comfort of passenger cars includes several factors, such as vehicle/package, social factors, individual factors, and the seat. The individual factors of comfort within automobile design are the most complicated to satisfy. They are covered in the literature under several indicators such as posture [5-9], anthropometrics [10-16], demography [6, 10-15, 17], fatigue [18-20], distribution of pressure on the seat $[9,16,21,22]$, and age $[12,17]$. Driver performance, including factors such as accuracy and speed, combined with time pressure often results in road traffic crashes and serious injuries and death 
[23]. Many people worldwide are killed or severely injured in motor vehicle accidents, so special attention also has to be paid to health and safety issues [5, 24, 25].

Accordingly, the compatibility of the anthropometric characteristics of the driver of the vehicle and its interior space dimensions including the dimensions and position of the devices and equipment in the car cabin directly affects the user. Those effects, in a broad scope, include the drivers' comfort, health, and working ability and influence performance, productivity, and financial losses, as well as the safety of the environment.

On the other hand, the various populations of passenger car users and the differences in these populations are extremely rarely examined deeply, although it is known that each population has a certain unique set of characteristics and needs that must be considered in designing an automotive product for an intended market segment. According to Kolich [26], the vehicle industry rarely examines different populations and does not pay full attention to all market segments [26], while authors in [24, 27] point out the importance of the target, not the general populations' anthropometric data collection and analysis.

It is also evident that research in the wide field of ergonomics is very scarce in the Libyan context. One of the rare surveys by Al-Ghaweel et al. [28] shows that road traffic accidents are the number one killer in Libya, placing Libya as the third most dangerous place to drive after Eritrea and Egypt. Accordingly, it would be relevant to offer the first study of the anthropometric characteristics of male automobile drivers in Libya. Traffic accident costs in Serbia are growing fast with a linear trend [29]. Surveys of the anthropometric measurements of Serbian passenger car drivers were conducted before 2014 by some of the authors of this survey [10-15], and an update is needed.

It is also important to point out that traffic injuries result in nearly 6 million deaths and incur 52 million disabilityadjusted life years annually, making up 15\% of the global health burden [30]. More than $90 \%$ of this burden occurs in low- and middle-income countries [28], such as Libya and Serbia.

The anthropometric data appear to be used mainly by universities and research institutions, although many industries, including the automobile industry, need dynamic anthropometric data [31]. Hence, the aim of this survey is to collect up-to-date anthropometric data on male passenger car drivers in Serbia and Libya and to compare the collected data. Since geographical origin, nutrition, social status, and the ethnic composition of populations are some of the general factors influencing the distribution of anthropometric characteristics [32], we expect to find differences between the observed samples. The survey is based on the anthropometric data of 921 Serbian and 300 Libyan male drivers. We have focused on male drivers, due to the fact that the drivers' sample in Libya did not include female participants (that population is extremely small). After the introduction provided in Section 1, the previous research is presented in Section 2. Section 3 describes the methodology, including statistical data analysis and interior space modeling. Section 4 offers a discussion of the examined populations and their interior space needs, while Section 5 provides conclusions.

\section{Previous Research}

Klarin et al. $[12,13,15]$ have collected anthropometric data on Serbian car drivers and discussed an adaptation of anthropometric measurements to the technical limitations of the car, in order to improve the comfort, safety, and efficiency of vehicle operation. The sample in a survey [11] contained 827 men and 41 women drivers, while survey [13] included 235 men and 13 women drivers. According to a new method for designing the part of the interior of standard passenger vehicles, where the foot controls are located as an indivisible part of the whole interior, and using interrelated functional links of anthropometric limitations, the study [15] determined the interior passenger car space for foot controls accommodation.

The authors in [14] showed that the passenger car is still not sufficiently adapted to a Serbian driver and offered a solution for the design for the space behind the windscreen, the position of the steering wheel, and the position of the foot controls together with the total space which the driver occupies, primarily from the aspect of anthropometric limitations. They concluded that the maximum width for accommodation of the driver at the lowest level of a seat along the $x$-axis is $169 \mathrm{~mm}$ and along the $y$-axis is $1013 \mathrm{~mm}$. The study [15] established that, in addition to the angles between the anthropometric measurements, the optimization of interior passenger car space, in terms of ergonomic adjustment, is most heavily influenced by the totals of the anthropometric measurements for lower leg length, upper leg length, and sitting height for the same overall totals, which are individually different.

In [24], anthropometric data from 1,405 male and female Malaysian drivers were collected, and the dimensions of a new driver's seat were determined. The authors in [33] analyzed the influence of body structure on the propagation of vertical vibration in selected regions of a seated human body and determined the relationship between selected values characterizing dynamic properties and the basic anthropometric parameters of a human body. The survey [34] used a sample of 32 participants and arrived at the conclusion that the hand measurements are correlated with body height. Park et al. [35] found a difference in the preferred driving posture between two ethnicities, Koreans and Caucasians. A laboratory study of 68 adult drivers found that seat height, steering wheel position, and seat cushion angle have considerable effects on posture and concluded that a driver adapts to changes in the vehicle and seat geometry through limb posture, while torso posture remains fairly constant [36]. The authors of the study [22] investigated whether a set of parameters derived from seat pressure mapping are sensitive enough to differentiate between different seats and whether they correlate with anthropometry in linear models and find that anthropometric data are very important. It can also be concluded that anthropometric data on car drivers are 
not often collected and analyzed nor presented in research articles, although the industry needs it.

There is also the significantly dynamic nature of anthropometric measurements. It leads to the conclusion that not only the collecting but also the updating of anthropometric data is a vital task for ergonomic design. In this context, Klarin et al. [14] have also pointed out the fact that anthropometric measurements change over time. Heights have increased, whereas other dimensions, that is, foot length, shoulder width, and hip width, have varied too, and therefore anthropometric measurements should be continuously monitored. Guan et al. [37] also concluded that there were anthropometric changes in width and girth between (truck) drivers across time. Accordingly, they have to be constantly monitored.

The importance of anthropometric measurements is highlighted by the fact that driving for extended periods of time inevitably leads to musculoskeletal symptoms and is associated with disorders of the spine, deep vein thrombosis, and similar problems [38-40]. Restricted postures, repetitive movements, vibration, continuous attention to the road, and stress are the suspected risk factors for various disorders in drivers [39]. The anthropometry and head position are also important factors in predicting injury in traffic crashes [41], and this is an additional reason to collect and analyze anthropometric data.

\section{Methodology}

The methodology includes anthropometric data collection and the comparison of anthropometric dimensions important for interior space modeling of two different populations, samples from Serbian male and Libyan male passenger car drivers.

The data of anthropometric measurements were collected by screening drivers arriving at random for the technical inspection of their vehicles at countrywide locations. Data on 921 Serbian and 300 Libyan male drivers were collected (women drivers are very rare in Libya, so that sample has not been collected). Study participants were informed of the objectives of the study (to gather data on anthropometric dimensions), told about the measurement procedures, and given the freedom to withdraw. Their ages varied from 18 to 72 years.

Before the data collection process, the body landmarks needed for the study were identified, to minimize repetition error. Also, participants' right side of the body was measured. Measurements included the eight basic anthropometric dimensions: standing height (STH), sitting height (SIH), lower leg length (LLL), upper leg length (ULL), shoulder width (SHW), hip breadth (HIB), arm length (ARL), and foot length (FOL), presented in $\mathrm{mm}$. The examined body dimensions of anthropometric measurements are shown in Figure 1.

In this study, the standard anthropometric instruments and procedures were used in data collection. International Society for the Advancement Kinanthropometry has determined well-known ISAK protocol, which was used in this study (described in detail in [42]). The participant was asked to take the appropriate position, according to ISAK protocol, prior to the measurement. The static anthropometry method, which involves measuring in the erect position during standing and sitting, in a manner so that the torso is at a $90^{\circ}$ angle with the upper leg, while the upper leg is at a $90^{\circ}$ angle with the lower leg, is used. Instruments such as an anthropometer, a beam caliper, sliding calipers, a stool, and a steel tape were used, similar to the procedures followed in previous research $[10-15,27,43]$. All dimensions were determined with clothes and footwear, similar to previous studies [21, 22]. In taking each measurement, two experienced, well-trained measurers participated, and each of the anthropometric dimensions was measured twice, by each of the measurers. After measurement, each value is written, checked by other measurers, and later on, inserted in database.

3.1. Statistical Data Analysis. Analysis of the obtained data was based on the use of the following statistical methods:

(i) Descriptive statistics

(ii) Correlation analysis between variables for Serbians and Libyans

(iii) Comparison of differences between variables for Serbian and Libyan male drivers, using adequate hypothesis testing

Descriptive statistics for all variables include a number of measurements: the mean, median, minimal value, maximal value, percentile values (1st, 5th, 95th, and 99th), rank, standard deviation, and coefficient of variation. Consequently, the Kolmogorov test for normality was conducted in order to determine the type of variables.

The possible relations between individual anthropometric measures within the separate samples, for Serbian and Libyan male drivers, were examined using correlations. The strength of the correlation bond, that is, the correlation coefficient, was based on the criteria such as those in $[44,45]$. Accordingly, criteria (1) in this study describe correlation strength and are as follows:

$$
\begin{aligned}
& |r| \in[0.0,0.3) \text { little or no correlation }(\text { n.s. }), \\
& |r| \in[0.3,0.5) \text { low level of correlation }\left({ }^{*}\right), \\
& |r| \in[0.5,0.7) \text { moderate correlation exists }\left({ }^{* *}\right), \\
& |r| \in[0.7,0.9) \text { there exists high correlation }\left({ }^{* * *}\right), \\
& |r| \in[0.9,1.0] \text { very high correlation }\left({ }^{* * * *}\right) .
\end{aligned}
$$

Last, anthropometric measurements were compared between the samples of Serbian and Libyan male drivers in order to obtain information on the possible differences which influence the design of interior passenger car space for these two markets. For $Z$-test for comparison of means, the comparison criteria are as given in [46, 47]. Accordingly, for normally distributed but independent populations, criteria (2), described as 


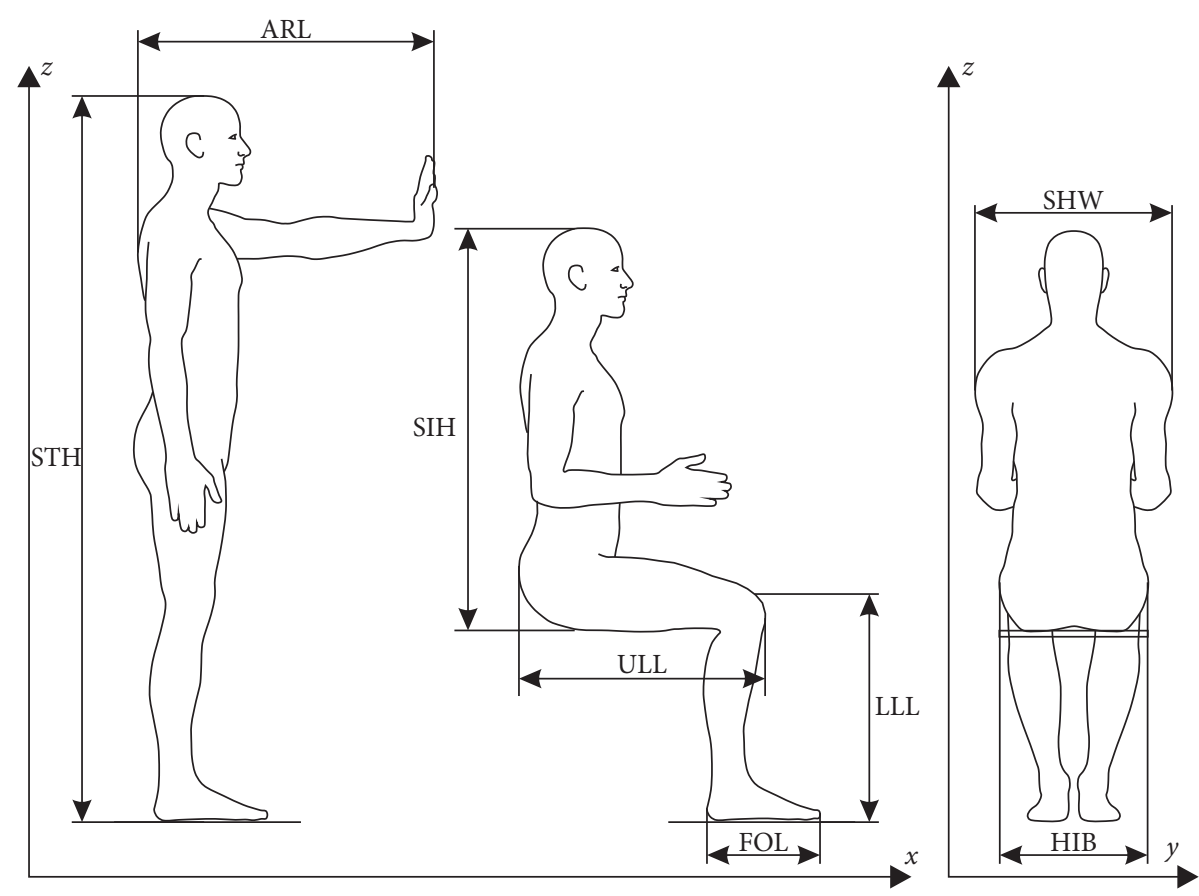

Figure 1: Body dimensions as anthropometric measurements [13].

$$
\begin{aligned}
& p>0.05 \text { for reliability less than } 95 \% \text { (n.s.), } \\
& p<0.05 \text { for } 95 \% \text { reliability, } \\
& p<0.01 \text { for } 99 \% \text { reliability, } \\
& p<0.001 \text { for } 99.9 \% \text { reliability, }
\end{aligned}
$$

will be used.

3.2. Descriptive Statistics for Serbian and Libyan Male Drivers. Descriptive statistic results are shown in Table 1 for Serbian male drivers and in Table 2 for Libyan male drivers.

For both sample groups, the coefficient values of variation are small $(<30 \%)$, which indicates that data are homogeneous for all variables for both Serbian and Libyan male drivers. Accordingly, additional examinations of data were conducted by the Kolmogorov test for normality (Tables 1 and 2), with which it is shown that all examined data are normally distributed. This enables the use of parametric methods in further statistical analysis, that is, the use of simple linear regression and correlation, as well as $Z$ test for the comparison of mean variable values in order to obtain valuable statistical conclusions on experimental data.

3.3. Linear Regression and Correlation Analysis between Measurements for Libyans. Based on the normality of measured variables for Serbian and Libyan male drivers, adequate simple linear regression and correlation analysis between variables in both groups were conducted.

For both groups, 28 correlations between anthropometric measurements were analyzed as presented in Table 3 (Serbian male drivers) and Table 4 (Libyan male drivers).
According to criteria (1), regarding the strength of correlation bond, that is, the correlation coefficient, there exist 19 (67.85\%) significant correlations between measured variables for Serbian male drivers. 10 of them have low levels of correlation, and 8 have moderate levels of correlation, while one is with a high level of correlation.

The number of statistically significant correlations, according to criteria (1), between measured variables for Libyan male drivers, is 11 , that is, $39.28 \%$. Six of them are at a low level, while the rest of them (five) have a moderate correlation dependency level. Therefore, the number of correlations is smaller for Libyan than for Serbian drivers.

For the Serbian and Libyan male drivers, there are 10 common relations with statistically significant correlations, which amount to $52.63 \%$ of correlations for Serbians and 90.91\% for Libyans.

3.4. Comparisons of Means between Anthropometric Measurements of Serbian and Libyan Male Drivers. The third step in the analysis of measured variables refers to comparisons of their mean values between Serbian and Libyan male drivers. For that purpose, a $Z$-test for comparison of means was used (Table 5). Furthermore, data on the compared values of means of measured variables are presented in Figures 2 and 3.

The results from Table 5, following criteria (2), regarding certain $\mathrm{p}$-level and reliability, indicate that all variables, that is, anthropometric measurements, are statistically absolutely larger for Serbian male drivers than for Libyan male drivers, except in the case of shoulder width where the mean results are the same, with no significant statistical differences. 
TABle 1: Descriptive statistics for Serbian male drivers.

\begin{tabular}{lccccccccccccccccc}
\hline Dim. & $N$ & Mean & Med. & Min. & Max. & $P 1$ & $P 5$ & $P 95$ & $P 99$ & $R$ & SD & $c_{v}(\%)$ & $D$ & $p$ & Sign. & VT \\
\hline STH & 921 & 1811.26 & 1800 & 1640 & 1995 & 1650.00 & 1690.0 & 1940.0 & 1980.00 & 355 & 74.657 & 4.12 & 0.167 & 1 & $n . s$. & Parameter \\
SIH & 921 & 917.218 & 920 & 780 & 1020 & 790.00 & 840.00 & 990.00 & 1010.00 & 240 & 47.064 & 5.13 & 0.155 & 1 & $n . s$. & Parameter \\
LLL & 921 & 593.613 & 600 & 470 & 690 & 492.00 & 530.00 & 650.00 & 680.00 & 220 & 35.754 & 6.02 & 0.162 & 1 & $n . s$. & Parameter \\
ULL & 921 & 636.228 & 635 & 490 & 800 & 510.00 & 570.00 & 710.00 & 738.00 & 310 & 45.544 & 7.16 & 0.204 & 1 & $n . s$. & Parameter \\
SHW & 921 & 471.356 & 470 & 390 & 630 & 390.00 & 400.00 & 570.00 & 590.00 & 240 & 46.728 & 9.91 & 0.154 & 1 & $n . s$. & Parameter \\
HIB & 921 & 391.097 & 390 & 310 & 590 & 320.00 & 340.00 & 470.00 & 590.00 & 280 & 43.749 & 11.19 & 0.243 & 1 & $n . s$. & Parameter \\
ARL & 921 & 706.488 & 700 & 500 & 830 & 580.00 & 640.00 & 790.00 & 800.00 & 330 & 46.213 & 6.54 & 0.188 & 1 & $n . s$. & Parameter \\
FOL & 921 & 281.612 & 275 & 250 & 320 & 255.00 & 265.00 & 300.00 & 315.00 & 70 & 12.577 & 4.47 & 0.176 & 1 & $n . s$. & Parameter \\
\hline
\end{tabular}

TABle 2: Descriptive statistics for Libyan male drivers.

\begin{tabular}{lcccccccccccccccccc}
\hline Dim. & $N$ & Mean & Med. & Min. & Max. & $P 1$ & $P 5$ & $P 95$ & $P 99$ & $R$ & SD & $c_{v}(\%)$ & $D$ & $p$ & Sign. & VT \\
\hline STH & 300 & 1749.517 & 1750 & 1570 & 1900 & 1609.90 & 1650.00 & 1850.00 & 1880.01 & 330 & 63.104 & 3.61 & 0.187 & 1 & $n . s$. & Parameter \\
SIH & 300 & 855.483 & 860 & 730 & 970 & 760.00 & 790.00 & 920.00 & 940.10 & 240 & 43.493 & 5.08 & 0.192 & 1 & $n . s$. & Parameter \\
LLL & 300 & 543.050 & 540 & 450 & 670 & 479.90 & 499.50 & 600.00 & 620.10 & 220 & 34.425 & 6.34 & 0.152 & 1 & $n . s$. & Parameter \\
ULL & 300 & 582.767 & 580 & 500 & 720 & 510.00 & 530.00 & 650.50 & 680.00 & 220 & 37.166 & 6.38 & 0.241 & 1 & $n . s$. & Parameter \\
SHWW & 300 & 471.350 & 470 & 380 & 640 & 389.90 & 400.00 & 550.00 & 580.10 & 260 & 45.440 & 9.64 & 0.166 & 1 & $n . s$. & Parameter \\
HIB & 300 & 365.620 & 360 & 230 & 570 & 280.00 & 290.00 & 470.00 & 540.00 & 340 & 59.192 & 16.19 & 0.202 & 1 & $n . s$. & Parameter \\
ARL & 300 & 633.053 & 610 & 540 & 800 & 540.00 & 550.00 & 800.00 & 800.00 & 260 & 72.291 & 11.42 & 0.222 & 1 & $n . s$. & Parameter \\
FOL & 300 & 275.833 & 275 & 265 & 300 & 265.00 & 265.00 & 295.00 & 295.00 & 35 & 9.115 & 3.30 & 0.213 & 1 & n.s. & Parameter \\
\hline
\end{tabular}

TABLE 3: The correlation between anthropometric measurements for Serbian male drivers.

\begin{tabular}{lccccccccccc}
\hline \multicolumn{2}{l}{ Comparison } & & $r$ & $r^{2}(\%)$ & Sign. & Comparison & $R$ & $r^{2}(\%)$ & Sign. & $r$ & $r^{2}(\%)$ \\
\hline STH & v.s. & SIH & 0.731 & 53.44 & $* * *$ & LLL & v.s. & SHW & 0.289 & 8.35 & $n . s$. \\
STH & v.s. & LLL & 0.577 & 33.29 & $* *$ & LLL & v.s. & HIB & 0.146 & 2.13 & $n . s$. \\
STH & v.s. & ULL & 0.522 & 27.25 & $* *$ & LLL & v.s. & ARL & 0.520 & 27.04 & $* *$ \\
STH & v.s. & SHW & 0.269 & 7.24 & $n . s$. & LLL & v.s. & FOL & 0.405 & 16.40 & $*$ \\
STH & v.s. & HIB & 0.084 & 0.71 & $n . s$. & ULL & v.s. & SHW & 0.380 & 14.44 & $*$ \\
STH & v.s. & ARL & 0.550 & 30.25 & $* *$ & ULL & v.s. & HIB & 0.253 & 6.40 & $n . s$ \\
STH & v.s. & FOL & 0.596 & 35.52 & $* *$ & ULL & v.s. & ARL & 0.492 & 24.21 \\
SIH & v.s. & HIB & 0.099 & 0.98 & $n . s$. & ULL & v.s. & FOL & 0.413 & 17.06 \\
SIH & v.s. & LLL & 0.440 & 19.36 & $*$ & SHW & v.s. & HIB & 0.610 & 37.21 & $*$ \\
SIH & v.s. & ULL & 0.362 & 13.10 & $*$ & SHW & v.s. & ARL & 0.317 & 10.05 \\
SIH & v.s. & SHW & 0.301 & 9.06 & $*$ & SHW & v.s. & FOL & 0.165 & 2.72 & $n . s$. \\
SIH & v.s. & ARL & 0.602 & 36.24 & $* *$ & HIB & v.s. & ARL & 0.066 & 0.44 & $n . s$. \\
SIH & v.s. & FOL & 0.395 & 15.60 & $*$ & HIB & v.s. & FOL & 0.147 & 2.16 \\
LLL & v.s. & ULL & 0.645 & 41.60 & $* *$ & ARL & v.s. & FOL & 0.386 & 14.90 & $n . s$. \\
\hline
\end{tabular}

TABLE 4: The correlation between anthropometric measurements for Libyan male drivers.

\begin{tabular}{lcccccccccccc}
\hline \multicolumn{2}{l}{ Comparison } & & $r$ & $r^{2}(\%)$ & Sign. & Comparison & $R$ & $r^{2}(\%)$ & Sign. & $r$ & $R^{2}(\%)$ \\
\hline STH & v.s. & SIH & 0.541 & 29.27 & $* *$ & LLL & v.s. & SHW & 0.303 & 9.18 & $*$ \\
STH & v.s. & LLL & 0.568 & 32.26 & $* *$ & LLL & v.s. & HIB & 0.215 & 4.62 & $n . s$. \\
STH & v.s. & ULL & 0.549 & 30.14 & $* *$ & LLL & v.s. & ARL & 0.186 & 3.46 & $n . s$. \\
STH & v.s. & SHW & 0.166 & 2.76 & $n . s$. & LLL & v.s. & FOL & 0.404 & 16.32 & $*$ \\
STH & v.s. & HIB & 0.122 & 1.49 & $n . s$. & ULL & v.s. & SHW & 0.292 & 8.53 & $n . s$. \\
STH & v.s. & ARL & 0.139 & 1.932 & $n . s$. & ULL & v.s. & HIB & 0.248 & 6.15 \\
STH & v.s. & FOL & 0.410 & 16.81 & $*$ & ULL & v.s. & ARL & 0.189 & 3.57 & $n . s$. \\
SIH & v.s. & LLL & 0.238 & 5.66 & $n . s$. & ULL & v.s. & FOL & 0.330 & 10.89 \\
SIH & v.s. & ULL & 0.231 & 5.34 & $n . s$. & SHW & v.s. & HIB & 0.593 & 35.16 & $*$ \\
SIH & v.s. & SHW & 0.182 & 3.31 & $n . s$. & SHW & v.s. & FOL & 0.195 & 3.80 & $n . s$. \\
SIH & v.s. & HIB & 0.140 & 1.96 & $n . s$. & SHW & v.s. & ARL & 0.110 & 1.21 & $n . s$. \\
SIH & v.s. & ARL & 0.169 & 2.86 & $n . s$. & HIB & v.s. & ARL & 0.321 & 10.30 & $*$ \\
SIH & v.s. & FOL & 0.207 & 4.28 & $n . s$. & HIB & v.s. & FOL & 0.058 & 0.34 & $n . s$. \\
LLL & v.s. & ULL & 0.698 & 48.72 & $* *$ & ARL & v.s. & FOL & 0.020 & 0.04 & $n . s$. \\
\hline
\end{tabular}


TABle 5: Comparison between Serbian male drivers and Libyan male drivers.

\begin{tabular}{lcc}
\hline$Z$-test & $p$-value & Sign. \\
\hline STH SMD > STH LMD & 0 & $p<0.001$ \\
SIH SMD > SIH LMD & 0 & $p<0.001$ \\
LLL SMD > LLL LMD & 0 & $p<0.001$ \\
ULL SMD > ULL LMD & 0 & $p<0.001$ \\
SHW SMD = SHW LMD & 1 & $n . s$. \\
HIB SMD > HIB LMD & 0 & $p<0.001$ \\
ARL SMD > ARL LMD & 0 & $p<0.001$ \\
FOL SMD > FOL LMD & 0 & $p<0.001$ \\
\hline
\end{tabular}

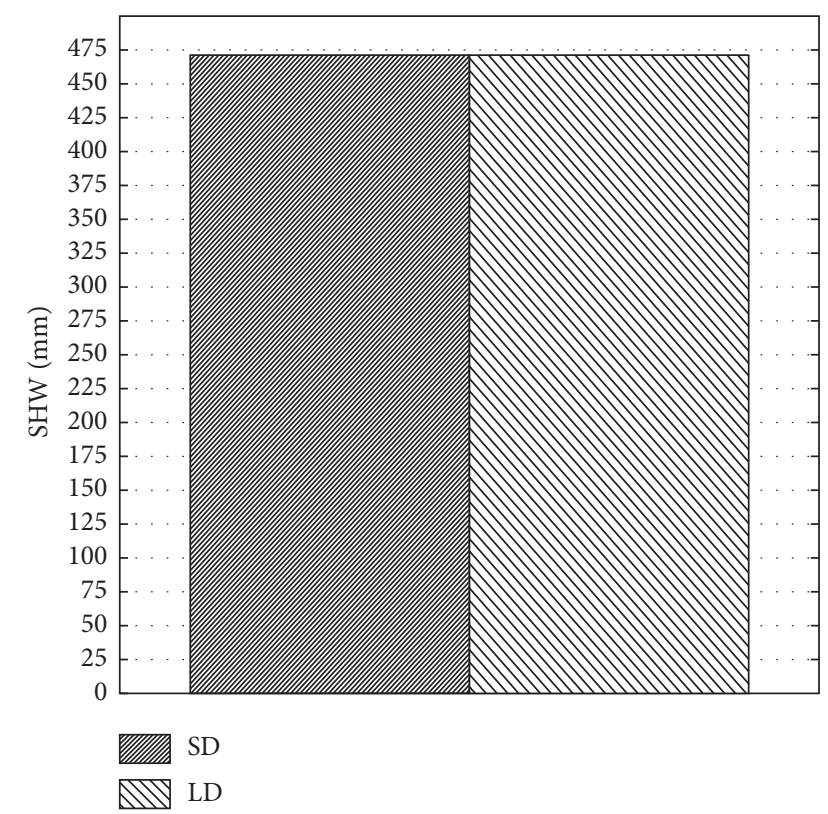

FIgURe 2: Ratio between shoulder width means for Serbian male drivers and Libyan male drivers.

3.5. Multivariate Anthropometric Modeling. The modeling of the interior space was conducted for both univariate (5th and 95th percentiles) and multivariate representative operators' models, given in Tables 6 and 7, using methodology described in detail in Essdai et al. [48].

\section{Discussion}

Planning the interior vehicle space and the dimensioning and positioning of the control elements must be based on the data on the anthropometric characteristics of the driver. By designing a workplace and space without using the anthropometric characteristics of the population that will use this workplace, it is impossible to achieve the conditions in which drivers will feel comfortable and safe. In fact, the loads that can arise while driving a vehicle are mainly associated with uncomfortable driving positions that are a consequence of the nonconformity of the dimensions of the vehicle cabin and the positions of the control elements of the vehicle with the anthropometric characteristics of the driver [7]. It is very important to determine the anthropometric characteristics of the user population, not the general population, as previous research shows. In our survey, correlation analysis was

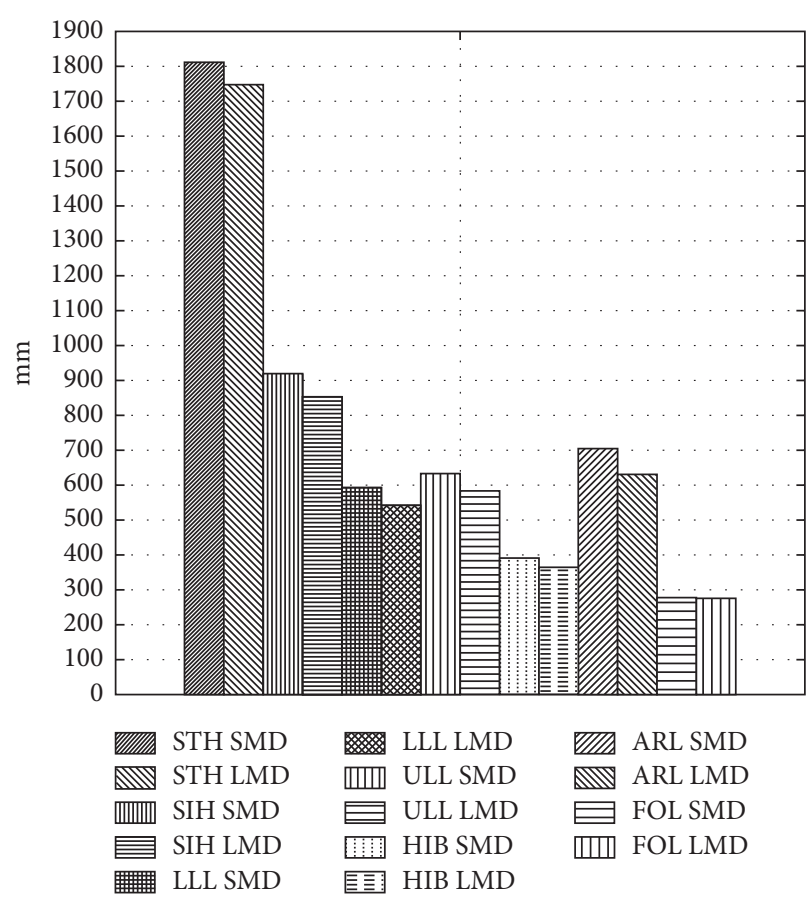

FIgURE 3: Ratio between means of anthropometric measurements between Serbian male drivers and Libyan male drivers.

conducted for all dimensions, for both samples separately, Serbian male drivers and Libyan male drivers.

As it was mentioned previously, for Serbian male drivers, 19 measurements are in correlation, which amounts to $67.85 \%$ of measured variables (Table 3 ). There are 10 correlations with a statistically low level with coefficients of correlation in the range from 0.301 to 0.492 , and coefficients of determination range from $9.06 \%$ to $24.21 \%$. Those correlations are present between sitting height and lower leg length, upper leg length, shoulder width, and upper leg length with shoulder width, arm length and foot length. Statistically, low level of correlation also exists between lower leg length and foot length, as well as between arm length and foot length. There exist 8 interrelationships between dimensions for Serbian male drivers which have statistically moderate strength correlations between 0.510 and 0.645 , with coefficients of determination in range from $26.01 \%$ to $41.60 \%$. Those interrelationships exist between standing height with lower leg length, upper leg length, arm length and foot length, lower leg length with upper leg length and arm length, as well as between shoulder width and hip breadth. The only statistically high-level significant correlation is between standing height and sitting height, with correlation coefficient which amounts to 0.731 and coefficient of determination $53.44 \%$.

Correlated measured variables for Serbian car drivers and their sums/numbers are presented in Table 8 .

Table 8 shows that foot length is mutually correlated with five other variables, while standing height, sitting height lower leg length, upper leg length, shoulder width, and hip breadth are mutually correlated with four other measured variables. Hip breadth is correlated with only one variable. 
TABLE 6: Anthropometric dimensions of representative body models of Serbian drivers including univariate percentiles of 95th and 5 th values.

\begin{tabular}{lcccccccc}
\hline Model & FOL & STH & SIH & LLL & ULL & SHW & HIB & ARL \\
\hline P95 & 305 & 1922 & 990 & 650 & 710 & 552 & 470 & 780 \\
P5 & 245 & 1650 & 820 & 520 & 550 & 390 & 330 & 610 \\
U & 310 & 1969 & 1002 & 663 & 722 & 546 & 432 & 798 \\
V & 245 & 1610 & 815 & 512 & 534 & 379 & 345 & 597 \\
X & 277 & 1737 & 853 & 578 & 634 & 533 & 486 & 678 \\
Z & 278 & 1842 & 964 & 597 & 622 & 392 & 290 & 717 \\
Y & 291 & 1823 & 943 & 544 & 568 & 487 & 393 & 703 \\
W & 264 & 1756 & 874 & 630 & 688 & 438 & 384 & 693 \\
A & 252 & 1645 & 807 & 570 & 620 & 444 & 419 & 631 \\
B & 269 & 1687 & 850 & 516 & 545 & 475 & 425 & 637 \\
C & 270 & 1747 & 913 & 526 & 538 & 394 & 313 & 660 \\
D & 252 & 1705 & 869 & 581 & 614 & 364 & 307 & 654 \\
E & 286 & 1832 & 903 & 648 & 717 & 530 & 463 & 735 \\
F & 303 & 1874 & 947 & 594 & 642 & 561 & 470 & 742 \\
G & 303 & 1933 & 1010 & 605 & 635 & 481 & 358 & 764 \\
H & 286 & 1891 & 966 & 659 & 711 & 450 & 352 & 758 \\
Min. & 245 & 1610 & 807 & 512 & 534 & 364 & 290 & 597 \\
Max. & 310 & 1969 & 1010 & 663 & 722 & 561 & 486 & 798 \\
\hline
\end{tabular}

TABle 7: Anthropometric dimensions of representative body models of Libyan drivers including univariate percentile 95th and 5 th values.

\begin{tabular}{lcccccccc}
\hline Model & FOL & STH & SIH & LLL & ULL & SHW & HIB & ARL \\
\hline P95 & 295 & 1840 & 920 & 600 & 650 & 550 & 470 & 790 \\
P5 & 245 & 1620 & 760 & 480 & 520 & 390 & 290 & 550 \\
U & 295 & 1895 & 934 & 626 & 662 & 547 & 422 & 695 \\
V & 250 & 1570 & 762 & 450 & 494 & 383 & 318 & 570 \\
X & 264 & 1668 & 807 & 531 & 568 & 548 & 502 & 720 \\
Z & 281 & 1798 & 890 & 546 & 588 & 381 & 239 & 544 \\
Y & 287 & 1715 & 788 & 547 & 577 & 520 & 379 & 487 \\
W & 258 & 1750 & 909 & 529 & 578 & 410 & 361 & 777 \\
A & 264 & 1598 & 741 & 492 & 527 & 503 & 424 & 561 \\
B & 247 & 1619 & 815 & 481 & 527 & 436 & 413 & 738 \\
C & 257 & 1694 & 864 & 490 & 539 & 339 & 261 & 636 \\
D & 274 & 1673 & 789 & 501 & 538 & 406 & 272 & 459 \\
E & 271 & 1793 & 907 & 576 & 617 & 524 & 469 & 805 \\
F & 289 & 1771 & 833 & 587 & 616 & 591 & 480 & 628 \\
G & 281 & 1868 & 955 & 584 & 629 & 427 & 316 & 703 \\
H & 298 & 1847 & 881 & 595 & 628 & 494 & 327 & 526 \\
Min. & 247 & 1570 & 741 & 450 & 494 & 339 & 239 & 459 \\
Max. & 298 & 1895 & 955 & 626 & 662 & 591 & 502 & 805 \\
\hline
\end{tabular}

The analysis of male drivers from Libya (Table 4), as it is mentioned above, shows that 11 of 28 relations have statistically significant correlations (39.28\%). Six of them have a statistically low level of correlation, while five of them have a statistically moderate level of correlation. Low-level correlations are with correlation coefficients in the range from 0.303 to 0.410 and with coefficients of determination from $9.18 \%$ to $17.06 \%$. Those correlations are between lower leg length and shoulder width and foot length, as well as between standing height and foot length, upper leg length and foot length, and hip breadth and arm length. For Libyan drivers, a statistically moderate level of correlation has
TABLE 8: Summary of number of statistically significant correlations between measures for Serbian male drivers.

\begin{tabular}{lccccccccc}
\hline SMD & STH & SIH & LLL & ULL & SHW & HIB & ARL & FOL & $\begin{array}{c}\text { Sum of } \\
\text { corr. }\end{array}$ \\
\hline STH & & $* * *$ & $* *$ & $* *$ & & & $* *$ & $* *$ & 4 \\
SIH & $* * *$ & & $*$ & $*$ & $*$ & & $* *$ & $*$ & 5 \\
LLL & $* *$ & $*$ & & $* *$ & & & & $*$ & 4 \\
ULL & $* *$ & $*$ & $* *$ & & & & & $*$ & 4 \\
SHW & & $*$ & & $*$ & & $* *$ & $*$ & & 4 \\
HIB & & & & & $* *$ & & & & 1 \\
ARL & $* *$ & $* *$ & & $*$ & $*$ & & & $*$ & 5 \\
FOL & $* *$ & $*$ & $*$ & $*$ & & & $*$ & & 5 \\
\hline
\end{tabular}

correlation coefficient values in the range between 0.515 and 0.698 and coefficients of determination in range of $26.52 \%$ to $48.72 \%$.

Moderate correlations exist between standing height and sitting height and lower leg length and upper leg length, as well as between shoulder width and hip breadth.

Correlated measured variables for Libyan car drivers and their sums/numbers are presented in Table 9.

Table 9 shows that, in case of Libyan male drivers, statistically significant interrelationships exist between standing height, lower leg length, and foot length and other four variables. Upper leg length is correlated with three other variables, and shoulder width and hip breadth are correlated with two other variables, while sitting height and arm length have statistically significant interrelationships with one other measured variable.

Serbian and Libyan male drivers have eight correlations which are common for both samples. Common correlations are those between hip breadth and foot length, standing height and sitting height, lower leg length, upper leg length, and foot length, and lower leg length and upper leg length and foot length, as well as between upper leg length and foot length and between shoulder width and hip breadth. Serbian male drivers have stronger correlations between standing height and sitting height and standing height and foot length compared to Libyan passenger car drivers. The rest of the correlations between dimensions have the same strength for both Serbian and Libyan drivers.

According to Tables 5 and 8, three common correlations for Serbian and Libyan drivers exist for standing height, foot length, lower leg length, and upper leg length, and one common correlation exists for shoulder width and hip breadth, while sitting height has one common correlation, and there are no common correlations for arm length.

The coefficient of variation in this survey is also comparable to previous research as given in [49], where it amounts to $3-21 \%$, while herein the values are between 3.30 and $17.07 \%$.

From the comparison of anthropometric measurements between samples for Serbian and Libyan drivers, it is obvious from Tables 5 and Figures 2 and 3 that most of the anthropometric measures for Serbians are statistically absolutely larger than for Libyans (Figure 3), where average differences vary from $2.10 \%$ for foot length up to $11.60 \%$ for arm length, with a majority of differences that exceed $6.67 \%$. 
TABLE 9: Summary of statistically significant correlations between measures for Libyan male drivers.

\begin{tabular}{lccccccccc}
\hline LMD & STH & SIH & LLL & ULL & SHW & HIB & ARL & FOL & $\begin{array}{c}\text { Sum of } \\
\text { corr. }\end{array}$ \\
\hline STH & & $* *$ & $* *$ & $* *$ & & & & $*$ & 4 \\
SIH & $* *$ & & & & & & & $*$ & 1 \\
LLL & $* *$ & & & $* *$ & $*$ & & & $*$ & 4 \\
ULL & $* *$ & & $* *$ & & & & & $*$ & 3 \\
SHW & & $*$ & & & $* *$ & & & 2 \\
HIB & & & & & $* *$ & & $*$ & & 1 \\
ARL & & & $*$ & $*$ & & $*$ & & \\
FOL & $*$ & & $*$ & $*$ & & & & \\
\hline
\end{tabular}

The only anthropometric measure that is the same for both samples is shoulder width, with the main difference in the range of $0.001 \%$ (as in Figure 2).

The study [15] used anthropometric data for drivers from Serbia from 1976 to 2007 and it proposes a methodology for interior space modeling that uses point " 0 " as the origin point of a coordinate system with $x$-, $y$-, and $z$-axes of the person-vehicle system and has shown that the anthropometric measurements for length have mechanical and mathematical functions that determine the width of the interior space together with shoulder-width measurements, while the floor-ceiling height of a vehicle is primarily affected by the anthropometric measurements of seating height and lower leg. Using multivariate models data from Tables 6 and 7 , interior space modeling in accordance with the methodology described in Brkić et al. [47], which has roots in survey [15], arrives at different space dimensions for Serbian and Libyan drivers, as shown in Figures 4 and 5. The required minimal space for the Serbian drivers amounts to $1500 \times 561 \times 1230 \mathrm{~mm}$. $X$-axis dimension is determined by the fixed point of the driver's heel in front of the accelerator pedal, and $y$-axis is determined by model $\mathrm{F}$ (with the largest shoulder width), while $z$-axis is obtained using model $G$, as in shown in Figure 4.

The minimal space required for Libyan drivers amounts to $1400 \times 591 \times 1155 \mathrm{~mm}$. Figure 5 illustrates the $x-z$ plane and shows that the minimal dimension on the $x$-axes is $1400 \mathrm{~mm}$ and on the $z$-axes is $1155 \mathrm{~mm}$. The arm reach is determined by model $E$ and amounts to $805 \mathrm{~mm}$, while foot accommodation is given by model $\mathrm{H}(298 \mathrm{~mm})$ along $x$-axes. The $y$-axis determined by model $\mathrm{F}$ amounts to $591 \mathrm{~mm}$ and represents the largest width.

\section{Conclusion}

Eight basic anthropometric dimensions-standing height, sitting height, lower leg length, upper leg length, shoulder width, hip breadth, arm length, and foot length - of Serbian and Libyan male drivers were summarized in this study. The anthropometric data presented herein constitute the first anthropometric database of a population of Libyan male drivers and update the base of Serbian male drivers. The analysis carried out shows that some statistical parameters, such as the variation and correlation coefficients, behave as expected and as observed in other populations, while

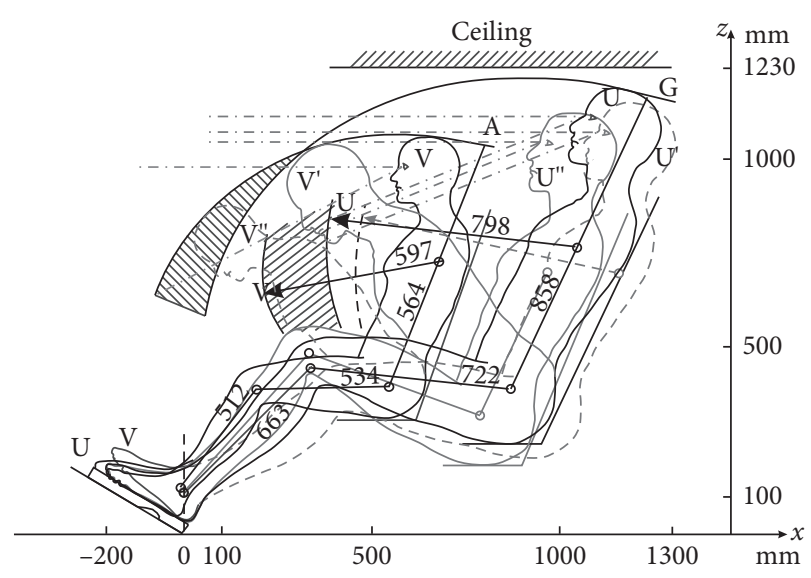

Figure 4: Space required for accommodation of Serbian car drivers, $x-z$ plane.

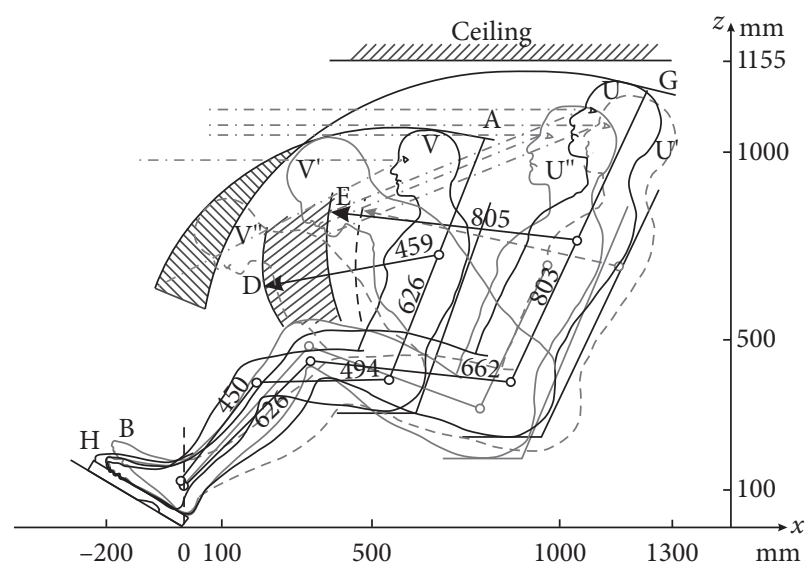

FIGURE 5: Space required for accommodation of Libyan car drivers, $x-z$ plane.

significant differences between the means of anthropometric measurements of Serbians and Libyans were found too, as expected. It also gives percentiles values for both populations, which are very useful for designers to match users' needs with technologically feasible solutions and later on to convert it into customer value and opportunity on a certain market.

Conducted research and statistical data analysis lead to the following conclusions, too:

(i) In the field of descriptive statistics, based on values of coefficients of variation and the consequently conducted Kolmogorov test for normality, it was concluded that all examined variables, for both Serbian and Libyan male drivers, are distributed according to normal distribution, which enables the use of the parametric method.

(ii) The conducting of simple linear regression and correlation leads to the conclusion that, for Serbian male drivers, a correlation between variables exists in $67.85 \%$ of cases, while $32.15 \%$ of variables are mutually uncorrelated. Likewise, for Libyan male drivers, a correlation between variables exists in 
$39.28 \%$ cases, while $60.72 \%$ of variables are mutually uncorrelated. Furthermore, ten correlations are common for both groups, which accounts for $52.63 \%$ of existing Serbian data correlations and $90.90 \%$ of Libyan data correlations. For Serbian male drivers, the common correlations are stronger in two cases, while for Libyan male drivers, only low and moderate correlations exist.

(iii) The comparison of mean values between variables for Serbian and Libyan male drivers showed that, beside shoulder width, all other variables have significantly higher values for Serbians than for Libyans.

(iv) The interior space dimensions of the vehicle for Serbian drivers amounted to $1500 \times 561 \times 1230 \mathrm{~mm}$ and for Libyan drivers amounted to $1400 \times 591 \times 1155 \mathrm{~mm}$. As expected, there is the smallest difference in interior space needed for driver accommodation on $y$-axis.

Ethnic and nutrition differences may provide an explanation for differences found between the two anthropometric samples. From our results, it is obvious that Serbian and Libyan passenger car drivers cannot feel equally comfortable in the same car. Accordingly, the results of this study are useful to passenger car designers aiming to eliminate anthropometric inconsistencies and improve the health of drivers, but also as an aid in improving safety on the roads and for the performance and financial interests of car producers.

Future research should go in the direction of the interior space design of passenger cars that are to be marketed in Serbia and Libya. Research like this should also be continuous, due to changes in anthropometric measurements over time. We also expect to be able in a few years to analyze the data on Serbian and Libyan male drivers again, in order to detect changes and to see if any particular evolutions have occurred in the values of certain dimensions.

\section{Nomenclature}

Anthropometric Measurements

STH: Standing height $(\mathrm{mm})$

SIH: $\quad$ Sitting height $(\mathrm{mm})$

LLL: Lower leg length ( $\mathrm{mm}$ )

ULL: Upper leg length ( $\mathrm{mm})$

SHW: Shoulder width $(\mathrm{mm})$

HIB: Hip breadth (mm)

ARL: Arm length ( $\mathrm{mm}$ ).

Sample Participants

SMD: Serbian male drivers

LMD: Libyan male drivers.

Statistics

$N$ : $\quad$ Sample size

Med.: Median

Min.: Minimal value

Max.: Maximal value

$R: \quad$ Rank

$P 1: \quad$ 1st percentile
P5: $\quad$ 5th percentile

P95: $\quad$ 95th percentile

P99: $\quad$ 99th percentile

SD: $\quad$ Standard deviation

$c_{\mathrm{v}}(\%)$ : Coefficient of variation

D: Kolmogorov statistics

$p$ : $\quad p$-value

Sign.: Significance

n.s.: Not significant

VT: Variable type

$r$ : $\quad$ Coefficient of correlation

$r_{2}$ (\%): Coefficient of determination

$z: \quad Z$-test for difference of means

p: $\quad$ Significance level.

\section{Data Availability}

The data of anthropometric measurements (marked in text with “*”) used to support the findings of this study may be released in aggregate form upon application to the Ethical Committee University of Belgrade, Faculty of Mechanical Engineering, and the corresponding author, who can be contacted at ndondur@mas.bg.ac.rs and zveljkovic@ mas.bg.ac.rs.

\section{Conflicts of Interest}

The authors declare no potential conflicts of interest with respect to the research, authorship, and publication of this paper.

\section{Acknowledgments}

This survey would not have been possible without the financial support of the MESTD (TR35017 and E13300). The authors would also like to express their acknowledgment to the companies involved and participants in Serbia and Libya who have willingly participated in the data collection.

\section{References}

[1] J. Lyons, "Factors contributing to low back pain among professional drivers: a review of current literature and possible ergonomic controls," Work, vol. 19, no. 1, pp. 95-102, 2002.

[2] W. Wang, J. Xi, and H. Chen, "Modeling and recognizing driver behavior based on driving data: a survey," Mathematical Problems in Engineering, vol. 2014, Article ID 245641, 20 pages, 2014.

[3] C. Viviani, P. M. Arezes, S. Bragança, J. Molenbroek, I. Dianat, and H. I. Castellucci, "Accuracy, precision and reliability in anthropometric surveys for ergonomics purposes in adult working populations: a literature review," International Journal of Industrial Ergonomics, vol. 65, pp. 1-16, 2018.

[4] S. Pheasant and B. Steenbekkers, "Anthropometry and the design of workspaces," Evaluation of Human Work, J. Wilson and N. Corlett, Eds., Taylor \& Francis, Boca Raton, FL, USA, pp. 706-754, 2005.

[5] J.-C. Chien, J.-D. Lee, and L.-C. Liu, "A fuzzy rules-based driver assistance system," Mathematical Problems in Engineering, vol. 2015, Article ID 207675, 14 pages, 2015. 
[6] M. Kolich, "A conceptual framework proposed to formalize the scientific investigation of automobile seat comfort," Applied Ergonomics, vol. 39, no. 1, pp. 15-27, 2008.

[7] K. M. Black, A. Lis, and M. Nordin, "Association between sitting and occupation low back pain," Ação Ergonômica, vol. 1, no. 3, pp. 73-86, 2002.

[8] B. Rajput and R. J. Abboud, "The inadequate effect of automobile seating on foot posture and callus development," Ergonomics, vol. 50, no. 1, pp. 131-137, 2007.

[9] G. Andreoni, G. C. Santambrogio, M. Rabuffetti, and A. Pedotti, "Method for the analysis of posture and interface pressure of car drivers," Applied Ergonomics, vol. 33, no. 6, pp. 511-522, 2002.

[10] M. M. Klarin and J. M. Cvijanovic, "The optimization of the interior of the passenger car," International Journal of Vehicle Design, vol. 19, no. 4, pp. 448-453, 1998.

[11] M. M. Klarin, J. M. Cvijanovic, and V. K. S. Brkić, "Additional adjustment of the driver seat in accordance with the latest anthropometric measurements of drivers in Belgrade," Proceedings of the Institution of Mechanical Engineers, Part D: Journal of Automobile Engineering, vol. 215, no. 6, pp. 709$712,2001$.

[12] M. M. Klarin, V. K. Spasojević-Brkić, P. D. Stanojević, and Z. D. Sajfert, "Anthropometrical limitations in the construction of passenger vehicles: case study," Proceedings of the Institution of Mechanical Engineers, Part D: Journal of Automobile Engineering, vol. 222, no. 8, pp. 1409-1419, 2008.

[13] M. M. Klarin, V. K. Spasojević-Brkić, Z. D. Sajfert, A. G. Žunjić, and M. S. Nikolić, "Determination of passenger car interior space for foot controls accommodation," Proceedings of the Institution of Mechanical Engineers, Part D: Journal of Automobile Engineering, vol. 223, no. 12, pp. 1529-1547, 2009.

[14] M. M. Klarin, V. K. Spasojević-Brkić, Z. D. Sajfert, D. B. Djordjević, M. S. Nikolić, and D. Z. Ćoćkalo, "Determining the width of the optimal space needed to accommodate the drivers of passenger vehicles using the analogy of anthropometric measurement dynamics and mechanical mechanisms," Proceedings of the Institution of Mechanical Engineers, Part D: Journal of Automobile Engineering, vol. 225, no. 4, pp. 425-440, 2011.

[15] M. M. Klarin, V. K. Spasojević-Brkić, Z. D. Sajfert et al., "Interior space design optimization of passenger cars in Serbia," Journal of Scientific \& Industrial Research, vol. 73, pp. 338-341, 2014.

[16] S. Hiemstra-van Mastrigt, L. Groenesteijn, P. Vink, and L. F. M. Kuijt-Evers, "Predicting passenger seat comfort and discomfort on the basis of human, context and seat characteristics: a literature review," Ergonomics, vol. 60, no. 7, pp. 889-911, 2017.

[17] H. Fazlollahtabar, "A subjective framework for seat comfort based on a heuristic multi criteria decision making technique and anthropometry," Applied Ergonomics, vol. 42, no. 1, pp. 16-28, 2010.

[18] W. El Falou, J. Duchêne, M. Grabisch, Y. Langeron, and F. Lino, "Evaluation of driver discomfort during long-duration car driving," Applied Ergonomics, vol. 34, no. 3, pp. 249-255, 2003.

[19] S. K. Hewson and A. Craig, "A critical review of the psychophysiology of driver fatigue," Biological Psychology, vol. 55, no. 3, pp. 173-194, 2001.

[20] P. Thiffault and J. Bergeron, "Monotony of road environment and driver fatigue: a simulator study," Accident Analysis \& Prevention, vol. 35, no. 3, pp. 381-391, 2003.
[21] N. Mansfield, G. Sammonds, and L. Nguyen, "Driver discomfort in vehicle seats-Effect of changing road conditions and seat foam composition," Applied Ergonomics, vol. 50, pp. 153-159, 2015.

[22] G. Paul, N. Daniell, and F. Fraysse, "Patterns of correlation between vehicle occupant seat pressure and anthropometry," Work, vol. 41, no. 1, pp. 2226-2231, 2012.

[23] E. Rendon-Velez, P. M. van Leeuwen, R. Happee et al., "The effects of time pressure on driver performance and physiological activity: a driving simulator study," Transportation Research Part F, vol. 41, pp. 150-169, 2016.

[24] D. Mohamad, B. M. Deros, D. D. Daruis et al., "Comfortable driver's car seat dimensions based on Malaysian anthropometrics data," Iranian Journal of Public Health, vol. 45, no. 1, pp. 106-113, 2016.

[25] P. Cordellieri, F. Baralla, F. Ferlazzo et al., "Gender effects in young road users on road safety attitudes, behaviors and risk perception," Frontiers in Psychology, vol. 7, p. 1412, 2016.

[26] M. Kolich, Ergonomic modeling and evaluation of automobile seat comfort, Ph.D. Thesis, University of Windsor, Windsor, Canada, 2000.

[27] A. Zunjic, V. S. Brkic, M. Klarin et al., "Anthropometric assessment of crane cabins and recommendations for design: a case study," Work, vol. 52, no. 1, pp. 189-194, 2015.

[28] I. Al-Ghaweel, S. A. Mursi, J. P. Jack et al., "Factors affecting road traffic accidents in Benghazi, Libya," Journal of Family \& Community Medicine, vol. 16, no. 1, 7 pages, 2009.

[29] B. Antić, M. Vujanić, K. Lipovac et al., "Estimation of the traffic accidents costs in Serbia by using dominant costs model," Transport, vol. 26, no. 4, pp. 433-440, 2012.

[30] B. T. Stewart, I. K. Yankson, F. Afukaar et al., "Road traffic and other unintentional injuries among travelers to developing countries," Medical Clinics, vol. 100, no. 2, pp. 331-343, 2016.

[31] S. J. Park, M. Subramaniyam, K. Lee et al., "Investigation of a strategy for improving the Size Korea anthropometric database," Work, vol. 62, no. 1, pp. 1-10, 2019.

[32] T. K. Chuan, M. Hartono, and N. Kumar, "Anthropometry of the Singaporean and Indonesian populations," International Journal of Industrial Ergonomics, vol. 40, no. 6, pp. 757-766, 2010.

[33] A. Zuska and T. L. Stańczyk, "Analysis of the impact of selected anthropometric parameters on the propagation of vertical vibration in the body of a seated person . (driver)," Journal of Vibroengineering, vol. 17, no. 7, pp. 3936-3948, 2015.

[34] M. E. Mossey, Y. Xi, S. K. McConomy et al., "Evaluation of four steering wheels to determine driver hand placement in a static environment," Applied Ergonomics, vol. 45, no. 4, pp. 1187-1195, 2014.

[35] S. J. Park, C. B. Kim, and J. W. Lee, "Comfortable driving postures for Koreans," International Journal of Industrial Ergonomics, vol. 26, no. 4, pp. 489-497, 2000.

[36] M. P. Reed, M. A. Manary, C. A. Flannagan et al., "Effects of vehicle interior geometry and anthropometric variables on automobile driving posture," Human Factors, vol. 42, no. 4, pp. 541-552, 2000.

[37] J. Guan, H. Hsiao, B. Bradtmiller et al., "US truck driver anthropometric study and multivariate anthropometric models for cab designs," Human Factors, vol. 54, no. 5, pp. 849-871, 2012.

[38] N. Raffler, R. Ellegast, T. Kraus et al., "Factors affecting the perception of whole-body vibration of occupational drivers: an analysis of posture and manual materials handling and 
musculoskeletal disorders," Ergonomics, vol. 59, no. 1, pp. $48-60,2016$.

[39] M. Varela, D. Gyi, N. Mansfield et al., "Engineering movement into automotive seating: does the driver feel more comfortable and refreshed?," Applied Ergonomics, vol. 74, pp. 214-220, 2019.

[40] E. Ö. Bulduk, S. Bulduk, T. Süren et al., "Assessing exposure to risk factors for work-related musculoskeletal disorders using Quick Exposure Check (QEC) in taxi drivers," International Journal of Industrial Ergonomics, vol. 44, no. 6, pp. 817-820, 2014.

[41] C. W. Roberts, J. Toczyski, and J. R. Kerrigan, "Cervical spine injury in rollover crashes: anthropometry, excursion, roof deformation, and ATD prediction," Clinical Biomechanics, vol. 64, pp. 42-48, 2018.

[42] K. Norton, N. Whittingham, L. Carter et al., "Measurement techniques in anthropometry," Anthropometrica, vol. 1, pp. 25-75, 1996.

[43] V. K. Spasojević Brkić, Z. A. Veljković, T. Golubović et al., "Workspace design for crane cabins applying a combined traditional approach and the Taguchi method for design of experiments," International Journal of Occupational Safety and Ergonomics, vol. 22, no. 2, pp. 228-240, 2016.

[44] A. G. Asuero, A. Sayago, and A. G. Gonzalez, "The correlation coefficient: an overview," Critical Reviews in Analytical Chemistry, vol. 36, no. 1, pp. 41-59, 2006.

[45] D. J. Rumsey and D. Unger, U Can: Statistics for Dummies, John Wiley \& Sons, Hoboken, NJ, USA, 2015.

[46] D. C. Montgomery and G. C. Runger, Applied Statistics and Probability for Engineers, John Wiley \& Sons, Hoboken, NJ, USA, 2017.

[47] V. K. S. Brkić, G. D. Putnik, Z. A. Veljkovic et al., "Interface for distributed remote user controlled manufacturing: manufacturing and education sectors led view," in Handbook of Research on Human-Computer Interfaces, Developments, and Applications, pp. 363-391, IGI Global, Hershey, PA, USA, 2016.

[48] A. Essdai, V. K. Spasojević Brkić, T. Golubović et al., "Crane cabins' interior space multivariate anthropometric modeling," Work, vol. 59, no. 4, pp. 557-570, 2018.

[49] M. P. Barroso, P. M. Arezes, L. G. da Costa et al., "Anthropometric study of Portuguese workers," International Journal of Industrial Ergonomics, vol. 35, no. 5, pp. 401-410, 2005. 